\title{
Ethical Consideration on Development of Modern Ecological Agriculture in China
}

\author{
Chen Zeng ${ }^{1}$ \\ ${ }^{1}$ School of Education and Public Administration, Suzhou University of Science and Technology, Suzhou, China \\ Correspondence: Chen Zeng, School of Education and Public Administration, Suzhou University of Science and \\ Technology, Suzhou 215000, Jiangsu, China. E-mail: 284506762@qq.com
}

Received: June 26, 2013 Accepted: July 24, 2013 Online Published: August 31, 2013

doi:10.5539/ass.v9n13p299 URL: http://dx.doi.org/10.5539/ass.v9n13p299

\begin{abstract}
This paper discusses the importance of ecological agriculture from the perspective of ecological ethics. Firstly, it proposes issues encountered in the development process of ecological agriculture in China. Secondly, it develops the ecological ethics implication of ecological agriculture that ecological agriculture implies respect towards ecological value, reflects pursuit on ecological benefit and emphasizes emphasis on ecological safety. Thirdly, it makes an analysis of the development path of ecological agriculture.
\end{abstract}

Keywords: ecological agriculture, ecological ethics, ecological safety, ecological value, ecological benefit

Ecological agriculture is to summarize and absorb successful experiences in all kinds of agricultural production modes, apply ecological systems engineering method and modern science and technology, reasonably arrange agricultural production to make it attain the level of optimization and establish an agricultural production system that adjusts measures to local conditions under the principle of coordinated development of economy and environment and according to the principles of ecology, ecological economics, biology and cyclic regeneration of materials (Liang, 2011, March 20). Establishment of such a system calls for cooperation between several parties, not only cooperation between food production and other economic crops in terms of production, but also cooperation between multiple industries, such as, forestry, animal husbandry, avocation and fishery, etc. Realization of this system also requires support of technology. On one hand, the traditional agricultural essence should be inherited and carried forward; on the other hand, advanced science and technology should also be applied. In designing of an ecological project, we should follow the principle of sustainability, deal well with the relationships between economy, society and ecological environment and form a virtuous cycle between the three so as to ensure stable and orderly development of agricultural economy. (Li \& Min, 2001, July 12)

With regards to issues existing in current development of ecological agriculture in China, it is a must to strengthen the fundamental position of agriculture, choose an agricultural modernization path with Chinese characteristics, construct a long term mechanism in which industry promotes agriculture and urban cities promotes rural areas, adhere to the primary task of developing modern ecological agriculture, persist in the development outlook of sustainability and establish policy security and science and technology innovation and promotion system. It is also necessary to cultivate a new type of farmers who are educated and proficient in technology and operation and let hundreds of millions of farmers play a role of subject on the path of developing ecological agriculture.

\section{The Realistic Dilemma in Development of Ecological Agriculture in China}

\subsection{Theoretical System to Be Improved}

Ecological agriculture, in itself, is a complicated systematic project, which involves theories in multiple disciplines of economics, ecology, ethics and biology. Previous studies have mainly been conducted in a single discipline and, indeed, have achieved definite research achievements, which can be said to have been through and profound in a certain aspect. Nevertheless, these studies are insufficient in interaction of all aspects. In order to make up for disadvantages in this regard, it is necessary to improve studies on ecological agriculture. We need to transfer from a study perspective of a single discipline to a systematic and comprehensive study. We have to take consideration of multiple aspects on the basis of a profound survey and analysis of the current ecological agriculture mode, considering the factors of ecological regionalism, stability, harmony and durability, widely 
absorb experts and talents from multiple interfaces to take participation, refer to knowledge in multiple disciplines, comprehensively apply the coupling rule of all factors, the optimal design of structure, scientific classification system and objective evaluation method and construct a theoretical system of the ecological agriculture itself.

\subsection{Technical System to Be Complete}

Since ecological agriculture system is called system, it is constituted by multiple factors. However, factors occupy an ecological niche and ecological value and these factors interdepend and interact with each other. For example, in order to feed a goose in the pond, the first thing to do is to determine how many gooses the pond is able to contain. From a professional perspective, the number of gooses is restrained by multiple factors, such as, the age and size of the gooses, the variety and number of fishes, the capacity of the pond, the quality of the water body, the water temperature and the exchange speed of water. However, farmers may not take into consideration of the professional theoretical knowledge in their engagement in the breeding industry. They merely rely on their own experiences or the vicarious experiences they have simulated from others. Nevertheless, these experiences may not guarantee that all these farmers are able to obtain a good effect. Their deficiency in the professional theoretical knowledge and experiences leads to failure in designing a complicated system project. The key to the issue is that so far as the current ecological agricultural practice is concerned, study on technical measures is insufficient, and technical measures widely promoted are even more insufficient. Thus, the issue is how to inherit excellent traditional technology and how to bring in high tech scientific technology to help to study and promote technical measures.

\subsection{Policy Measures Need to Be Completed}

So far the current development of ecological agriculture, as the vast majority of farmers have not yet formed a good ecological protection habit and have not had strong ecological consciousness, it is necessary to depend on laws and regulations to make development of ecological agriculture generally promoted and support of the government is indispensable. The government facilitates development of ecological agriculture by means of establishing effective policy incentive mechanism and security system. The reform has promoted development of rural economy in China and is quite successful. However, it is not yet perfect and there is still room for improvement and some policies need to be more complete, such as, implementation of policies in ecological agriculture. As a result of incomplete of the policies, some farmers lose the land and water they have possessed and the basic rights farmers have shared fail to get appropriate and legal protection. The price of agricultural products is an extremely important factor in the practice of development of ecological agriculture. The price of agricultural products influences the economic benefit of farmers, relates to the immediately interests of farmers and directly stimulates the activities of engaging in ecological agriculture.

\subsection{Service Efficacy Needs to Be Improved}

It is true that technology is important, but service is also important. Local agricultural materials service can provide farmers with fine varieties, seedling, fertilizer, pesticide, technical support, credit and loan and information service. Nevertheless, in some backward areas, farmers are not entitled to share these basic services. In addition, credit and loan service is an extremely important factor, as farmers engaged in ecological agriculture practice have to wait for a long time to gain profits. Under such circumstance, credit and loan service is quite favorable and practical for farmers. In the meantime, as for farmers at an era of information explosion, information service becomes more and more important and has become a restraining factor in development of ecological agriculture. Farmers obtain effective information on agricultural materials through television, newspaper and even network and are able to adjust their production structure in due course and realize maximization of economic benefit. At the same time, vigorous development of all types of intermediary service organizations is also a feasible measure, such as, farmers' specialized cooperative economic organization and specialized village and specialized household of transportation and sale.

On the other hand, the incentive mechanism is quite necessary. However, after all, it is nothing more than an external incentive and long term external incentive and its effect may not last long. Thus, development of ecological agriculture is more inclined to develop a kind of internal incentive mechanism and cultivate the ecological agriculture consciousness of farmers and let farmers positively participate in this activity out of their own will. In order to fully mobilize the voluntariness and initiative of the vast majority of farmers and enable them to be occupied in ecological agricultural activities self-dependently, on one hand, we need to enhance our own service capacity and our service level. On the other hand, we should provide the vast majority of farmers with more abundant and high level training and learning opportunities.

\subsection{Promotion Strength Needs to Be Reinforced}


Development of ecological agriculture is aimed to promote ecological growth of rural areas and realize coordinated development of ecology, economy and society. However, in China, the phenomenon of disequilibrium development of economy in urban cities and rural areas and in different regions is still general. Especially in remote old mountain revolutionary base areas, rural economy needs to be urgently developed and the life level of people needs to be improved. However, these areas possess abundant natural resources and have the natural condition of developing ecological agriculture. It is just that the actual development of ecological agriculture does not fit with this demand. Farmers merely depend on planting on agricultural crops and simple agricultural production to obtain ecological benefit. This is far from enough for improving the living level of people. Globalization of world economy and the situation that China enters WTO are both a new opportunity and a new challenge for development of ecological agriculture in China. In order to adapt to this economic situation, we have to make preparations to welcome the opportunity and challenge and development of ecological agriculture has to clear away all obstacles that hinder its development, adjust the structure of agricultural industry and form a situation of agricultural industrialization, integration and networking. Besides, the issue of moral quality is a major issue that has been perplexing the development of the society. It is estimated by relative reports that, by the end of the 30s in this century, the population of China will face a new breakthrough and will get to more than 1.6 billion. The lasting growth of moral quality will bring enormous pressure on land resources and per capita agricultural cultivated land area will gradually decline. Accordingly, rural labor forces will transfer to urban cities, which may give rise to the dilemma of agricultural sustainable development in this area. Therefore, we have to be on guard against this dilemma and make sufficient preparations to welcome approaching of this challenge by means of extending the industrial chain and improving the specialized level of agriculture in ecological agriculture.

Although ecological agriculture emerged earlier in China and the meaning of developing ecological agriculture gradually came to the mind of people, its overage was low and promotion strength was far from enough. Therefore, the government needs to attach more importance to vigorously promote development of ecological agriculture. In addition to the heavy population pressure and inappropriate utilization of natural resources, water and soil loss, land deterioration, desertification, water and air pollution, ecological function deterioration of forest and grassland also restrain development of ecological agriculture. Thus, we should take into consideration of all factors that affect development of ecological agriculture from all aspects, make preparations ahead of time and improve fundamentally the trend of overall deterioration of ecological environment.

\section{Ecological Ethics Implication of Development of Ecological Agriculture in China}

\subsection{The Concept of Ecological Agriculture Reflects the Implication of Ecological Ethics}

The concept of "ecological agriculture" was, for the first time, proposed by the American soil scholar William Albrecht. In China, ecological agriculture is generally interpreted as applying principles and methods of multiple disciplines of ecological ethics, ecological economics and systematic science to combine organically achievements of modern science and technology and essence of traditional agricultural technology, integrate agricultural production, rural economic development and ecological environment governance and protection as well as protection and high efficiency utilization of resources and establish a new type of comprehensive agricultural production system that has ecological rationality and complete functions and that manifests virtuous cycle. (Li, 2003) It is definitely pointed out in this concept to integrate agricultural production, rural economic development and governance and protection of ecological environment as well as protection and high efficiency utilization of resources, with the aim of systematically expounding the moral relations between human kind and the natural environment, which is an implication of ecological ethics. This ecological ethics is the ethical concept, ethical behavior standard about the ecological environment relations in the relationship between man and man and between man and the life they lead and the moral practice that examines feasibility and effectiveness of this theory. This theory originates from the rational reflection of human being on the environmental disruption and deterioration they have caused in the process of promoting ecological development and even more serious ecological crisis. This ethical ethics also contains another philosophical meaning and it also acknowledges the value and rights of man and the nature. However, from the perspective of ecology, it more affirms the value and rights of the nature and regards the nature as the essence of ecological morality, attributes it as the basic scope of ecological morality and confirms the behavioral norm and principle to be followed by ecological morality, namely, respecting the nature and the life, protecting the ecological environment and maintaining harmony between man and the nature.

Development of ecological agriculture reflects the essential requirement of environmental protection and ecological ethics. Development of ecological agriculture is to test moral norm of ecology in social practice, a process of edification on ecological ethics, which is reflected in the three aspects of realization of ecological 
benefit, economic benefit and the ultimate target. In the practice of realization of ecological benefit, development of ecological agriculture advocates ecological benefit and maintains ecological balance, which reflects the fact that people yearn for scientific and correct recognition of the nature and the actual relations between man and the nature. In the practice of realization of economic benefit, as a kind of economic activity, development of ecological agriculture emphasizes the obligation and mission of maintaining ecological balance and people's demand on and desire for ecology, which reflects at the time of making use of the nature, people also show respect for the nature, embodying the moral concept of human orientation and harmonious development. In the practice of realization of the ultimate target of sustainable development of ecological agriculture, people are asked to discover and know about the value of the nature in the practice of developing ecological agriculture, attempt to attain equal co-existence of natural objects and harmonious goodwill and the ethical state of syncretism between heaven and man. This, to a certain extent, explains the ethical concept and obligation scope of ecological ethics.

\subsection{The Ecological Ethics Concept of Ecological Agriculture Reflects Respect towards Ecological Value}

According to the theory of system, the nature is a complicated ecological system that contains numerous mutually correlated factors. Agricultural ecological system is merely one of the numerous sub-systems, while this sub-system. That is, each biology existing in the agricultural ecological system, is a factor in this system and each factor occupies a certain position and has certain value, which is the ecological value. In ecological ethics, the concept of ecological value means that each natural object plays a crucial role relative to the ecological system and plays the role of stabilizing and balancing the ecological system. According to the definition of the ecological ethics in ecological agriculture, it is required that people abide by guidance of ecological ethics and follow the development rule of the nature at the time of engaging in activities of ecological agriculture. On the basis of maintain the environmental balance of agricultural ecology, it is necessary to rationally allocating agricultural production resources and adopting high efficiency development mode, and at the time of enhancing the natural recovery capacity of agricultural ecology system, the quantity of agricultural products realizes maximization and quality optimization to facilitate comprehensively healthy, harmonious and sustainable development of man and the nature (Liu, 2006).

\subsection{The Characteristic of Ecological Agriculture Emphasizes Pursuit of Ecological Benefit}

The characteristics of ecological agriculture mainly contain the four aspects of comprehensiveness, high efficiency, diversity and sustainability.

Ecological agriculture has comprehensiveness. With regards to the agricultural ecological system, ecological agriculture starts out from the overall function perspective, develops ecological agriculture system, focuses on constructing a cyclic and regenerative mode, makes planning by considering the overall situation and makes adjustment and optimization on the agricultural structure so as to enable agriculture, forestry, animal husbandry, avocation and fishery to develop comprehensively and guide coordination of all industries and bring out the best in each other to achieve the purpose of enhancing the comprehensive production capacity.

Ecological agriculture has diversity. As for the essence department in the traditional agriculture, ecological agriculture should widely absorb and retain and combine with modern science and technology to produce all kinds of ecological modes, engineering models and technical equipment. China has a vast area of territory and different areas have great discrepancy in terms of natural conditions, economic and social development level and resource base. Thus, ecological agriculture is able to make all areas play their local advantages, enhance advantages and avoid disadvantages, make industrial development and social development coordinated and combined with social need and practically realize adjustment of measures to local conditions.

Ecological agriculture has high efficiency. Ecological agriculture reduces agricultural costs and increases benefit through substance cycle and multi-level comprehensive utilization of energy. It adopts deep processing serialization to realize resource utilization of waste and realize economic value added. In the meantime, it also creates a lot of employment opportunities to enable plenty of surplus labor forces in rural areas to realize internal agricultural employment and the enthusiasm of farmers in participation in agriculture to get protected. (http://www.cusdn.org.cn/)

Ecological agriculture has sustainability. Ecological agriculture plays an important role in prevention and remedy of pollution, maintains ecological balance by adjusting ecology and finally improves the ecological environment to make economic development and environmental protection closely combined. Meanwhile, ecological agriculture is able to enhance safety of agricultural products and improve people's satisfaction with agricultural products. Development of ecological agriculture is also able to enhance motivation of agricultural development and improve stability of ecological system and rural economy and industrial sustainable development gets 
realized.

\subsection{The Content of Ecological Agriculture Establishes Emphasis on Ecological Safety}

With process of human kind, development of economy and development of agricultural production, agricultural production environment has manifested a more and more wretched tendency and the issue of ecological safety has threated the entire human kind and the entire globe. Safety of the system in itself and safety of human kind in itself constitute the major content of ecological safety. Thus, in the context of agricultural production, the issue of ecological safety mainly comes from the following two aspects.

On one hand, it is the aspect of safety of living species. Biocenosis is an important "gene pool", and is the most important material foundation that constitutes ecological safety. Once it is not practically protected, invasion of all kinds of harmful species may give rise to loss of biocenosis and ecological safety may probably go beyond repair after being damaged. Therefore, in the process of establishing agricultural ecology system, invasion of harmful agricultural biology should be kept on guard in agricultural production and other human activities so as to prevent soil family biology from being damaged and local ecological system from being destructed. In addition, feed supplement, agricultural pesticide and fertilizer also greatly threats safety of biocenosis.

On the other hand, it is the aspect of food safety. The issue of serious overproof pollutants in agricultural products has become a major threatening issue in the food safety in China. Besides, evaluation and risk of transgenic crops obvious increases. In order to resolve the potential threats of unprofitable agricultural products to human health, products produced should be "green food" or "ecological food" as far as possible.

From the perspective of ecological safety, in the activities of human kind engaging in ecological agricultural production, production of ecological food has everything to gain and nothing to lose. Firstly, ecological food is healthy and green, so it is to the benefit of human health and guarantees the personal safety and health of human kind. Secondly, production of ecological food is able to promote development of local agricultural economy and bring more and abundant material economic benefit to farmers so as to improve the living level of farmers. Thirdly, production of ecological food brings the minimum threat to the ecological environment and even has no threat. This is favorable to recovery of the ecological system and agricultural ecological environment gets maximum and most effective protection, which, from all aspects, promotes harmonious and sustainable development of man and the nature.

\section{Choice of Path for Development of Ecological Agriculture in China}

\subsection{Strengthening the Environmental Consciousness of Ecological Agriculture}

As a rule about the relationships between man and man and between man and the nature and a rule to deal with these relationships, ethics not only needs guarantee of the system, but also needs guidance of the public opinions for supervision. Development of ecological agriculture has to adhere to study on ecological ethics and the publicity and education on ecological ethics. This is helpful to cultivate the consciousness of ecological environment among people, establish the inclination to maintain balance of the ecological environment, advocate a healthy and civilized life environment idea, change the mode of rural residents in agricultural production, complete and improve construction of rural spiritual civilization and is more helpful for people to cultivate the ideological idea of ecological integration of "harmony between man and the nature". This ideological idea requires people to adhere to the scientific path of reduce, reuse, recycle and replace, namely, the " $4 \mathrm{R}$ " principle, in the process of engaging in activities of agricultural ecological production. (Ye, 2004)

\subsection{Adhering to the Path of Agricultural Cleaner Production}

The practice of agricultural production is faced with a series of such problems as food safety and safety of living species. In order to resolve these problems, it is a must to seek for a feasible agricultural production mode, which is required to take into consideration of the ecological value of biology within the ecological system, use such agricultural materials as fertilizer, agricultural pesticide and fodder and realize unification of economy, society and ecological benefit, which is called agricultural cleaner production. This new mode integrates the essence of traditional agriculture and modern agriculture and guarantees sustainable development of agriculture. Agricultural cleaner production absorbs the basic thought in industrial cleaner production. That is, it adopts the environmental strategy of overall prevention in the process of agricultural production to enhance efficiency of ecology and it requires to use green resources that are innocuous to the environment, such as, green pesticide, substance, fodder and fertilizer and adopts scientific production technology to prevent invasion of agricultural pollutants and reduce harm of human kind to the environment in the process of production. It defines the target of agricultural cleaner production, appropriately allocates natural resources, effectively controls generation and discharge of agricultural pollutants, prevents pollution of agricultural products, promotes harmonious 
compatibility of agricultural products with the environment in the process of production and utilization and reduces the hard of agricultural production activities on human kind and the environment. (Jia, 2004)

\subsection{Constructing an Industrial Chain of Modern Ecological Agriculture}

Ecological agriculture constructs a logistic system of the ecological industrial chain under the guidance of the technology o cyclic economy, establishes an information network of the industrial chain, uses knowledge of life cycle theory for supervision and evaluation, effectively controls consumption and discharge of the two endpoints in the traditional agricultural production, fully realizes "few investment, high output and low pollution", eliminates all factors that pollutes the environment, maintains balance of agricultural ecological environment and realizes harmonious and sustainable development of man and the nature. (Xiong \& Luo, 2005)

Agricultural ecological industrial chain connects supply of means of productions, agricultural products production and processing and subsequent storage and transportation, sales and consumption into an organic whole and involves the fields of planting industry, fishery industry, animal husbandry industry, agricultural products processing industry, agricultural products sales, service industry and agricultural products consumption. It forms a close ecological industrial chain net through exchange and cyclic utilization of waste, factor coupling and ecological chain. All these industrial fields constitute an organic whole with a certain proportion which are mutually correlated and which are interdependent and interact in terms of quality. For example, in the ecological industrial chain constituted by potato farm planting industry, sugaring processing industry, mature vinegar brewing industry, paper-making industry and environmental comprehensive processing industry, all departments have their production of products and are correlated with mutual utilization and exchange of the intermediary products, which forms a complete and closed ecological industrial net. Therefore, the resources are allocated in an optimal way, the wastes are effectively utilized and the environmental pollutants are reduced to the minimum level.

\section{References}

Jia, J. W. (2004). Theory and Practice for Agricultural Clean Production. Environment and Sustainable Development, (4), 3-6.

Li, W. H., \& Min, Q. W. (2001, July 12). Achievement, Issues and Development Prospect of Chinese Ecological Agriculture. Department of Science, Education and Rural Environment, Ministry of Agriculture. Ecological Agriculture and Sustainable Development. Beijing: China Agriculture Press.

Li, W. H. (2003). Ecological Agriculture: Theory and Practice of China Sustainable Agriculture. Beijing: Chemical Industry Press.

Liang, Q. W. (2011, March 20). Basic Experiences of German Boosting Modern Agriculture and Enlightenment to China. Guide of Sci-tech Magazine.

Liu, J. R. (2006). Ethical Appeal of Development of Ecological Agriculture. Journal of China University of Mining \& Technology (Social Science), (1), 23-29.

Ministry of Agriculture: Priority to Consideration of River Source in Special Project Support of Ecological Agriculture Construction. Retrieved from http://www.cusdn.org.cn/

Xiong, Y., \& Luo, L. H. (2005). Developing Cycle Economy and Promoting Agriculture Sustainable Development. Journal of Jiangxi Agricultural University (Social Sciences), (4).

Ye, C. W. (2004). Ecological Agriculture and National Ecological Safety. Science \& Technology Progress and Policy, (3), 17-19.

\section{Copyrights}

Copyright for this article is retained by the author(s), with first publication rights granted to the journal.

This is an open-access article distributed under the terms and conditions of the Creative Commons Attribution license (http://creativecommons.org/licenses/by/3.0/). 